\title{
Description of Achromobacter xylosoxidans Yabuuchi and Ohyama 1971
}

\author{
EIKO YABUUCHI, IKUYA YANO, SACHIKO GOTO, EIKI TANIMURA, \\ TOMIYOSHI ITO, and AKIO OHYAMA
}

\begin{abstract}
Department of Microbiology, Kansai Medical University, Moriguchi, Osaka; Department of Bacteriology, Osaka City University Medical School, Abeno-ku, Osaka; and Department of Microbiology, Toho University, School of Medicine, Ota-ku, Tokyo, Japan
\end{abstract}

\begin{abstract}
More than 70 characters of 55 strains of Achromobacter xylosoxidans were compared with those of the type strain of $A$. xylosoxidans, ATCC 27061 (= KM 543 ). Repeated examination of these 55 strains confirmed the stability of the flagellar morphology and biochemical reaction pattern and $r$ ismed that the species can be recognized by these characters. Two strains of Alcaligenes faecalis, two strains of Alcaligenes denitrificans, five strains of Alcaligenes sp., and five strains of each of King groups IIIa and IIIb were identified as strains of $A$. $x y$ losoxidans. The base compositions of the deoxyribonucleic acids of 20 strains are given. The cellular fatty acid composition of extractable and bound lipids of five strains was determined. The minimal characters for the identification of strains of $A$. xylosoxidans are presented.
\end{abstract}

Achromobacter xylosoxidans was named and described by Yabuuchi and Ohyama (13) after a study of seven strains isolated from purulent ear discharge of patients with chronic otitis media. The type strain, KM 543, was designated and deposited in several type-culture collections. Among 183 strains of nonfermenting, gram-negative rods received from several clinical laboratories since 1969,35 were identified as A. xylosoxidans. Twenty strains received from foreign investigators were subsequently identified as $A$. xylosoxidans. The uniformity of the flagellar morphology, biochemical reactions, cellular lipid and fatty acid composition, and the guanine plus cytosine (GC) mole percent of composition deoxyribonucleic acid (DNA) serve to establish the homogeneity of $A$. xylosoxidans. The purposes of this report are to offer evidence of the uniformity of the species, to amend the previous description (13), and to present the minimal characters for the identification of strains of $A$. xylosoxidans.

\section{MATERIALS AND METHODS}

The histories and corresponding accession numbers of 55 strains of $A$. xylosoxidans are listed in Table 1. Strains described in the literature $(3,6,9)$ are listed in Table 2.

A. $x y$ losoxidans ATCC 212 (= RH $137=\mathrm{KM} 1051)$ was isolated in 1923 and deposited in the American
Type Culture Collection by E. O. Jordan, University of Chicago, in 1925, and is the oldest strain of this species known to be available. The type strain, ATCC 27061 (KM 543), was isolated by H. Takeda, Kansai Medical University Hospital, from the purulent ear discharge of a 32-year-old female patient with otitis media chronica sinistra. It was isolated from a specimen collected during the patient's first visit for medical attention at Kansai Medical University Hospital on 8 July 1969, and was mixed with Staphylococcus aureus. The unidentified glucose nonfermenter, strain 9, was received from Takeda on 30 September 1969 and was designated KM 543 (13).

A broth culture was formalinized, washed twice with distilled water, and stained for flagella by the method of Leifson $(7,8)$. A distilled-water suspension, prepared from growth on an infusion agar (Difco 0045 ) slant, was also stained for flagella. Growth from infusion agar was suspended in formalinized saline, washed with distilled water, negatively stained with phosphotungstic acid, and observed for flagella in an electron microscope (Hitachi HU-12). Cultures for flagellar morphology were incubated at $20 \mathrm{C}$ for $18 \mathrm{~h}$. Spreading, diffuse growth emanated from the line of inoculation in motility medium after $18 \mathrm{~h}$ of incubation at $20 \mathrm{C}$ were examined microscopically in wet-mount preparations. Nonmotile strains were inoculated in the center of motility medium in a petri dish (Gard plate) to select actively motile cultures.

Growth in the following media was determined after incubation in an anaerobic environment (BBL GasPak anaerobic system): (i) OF basal medium (Difco 0688) containing $1 \%$ glucose; (ii) nitrate broth (3) (Casitone [Difco], $10 \mathrm{~g}$; yeast extract [Difco], $3 \mathrm{~g}$; 
TABLE 1. Histories and corresponding numbers of 55 Achromobacter xylosoxidans strains ${ }^{a}$

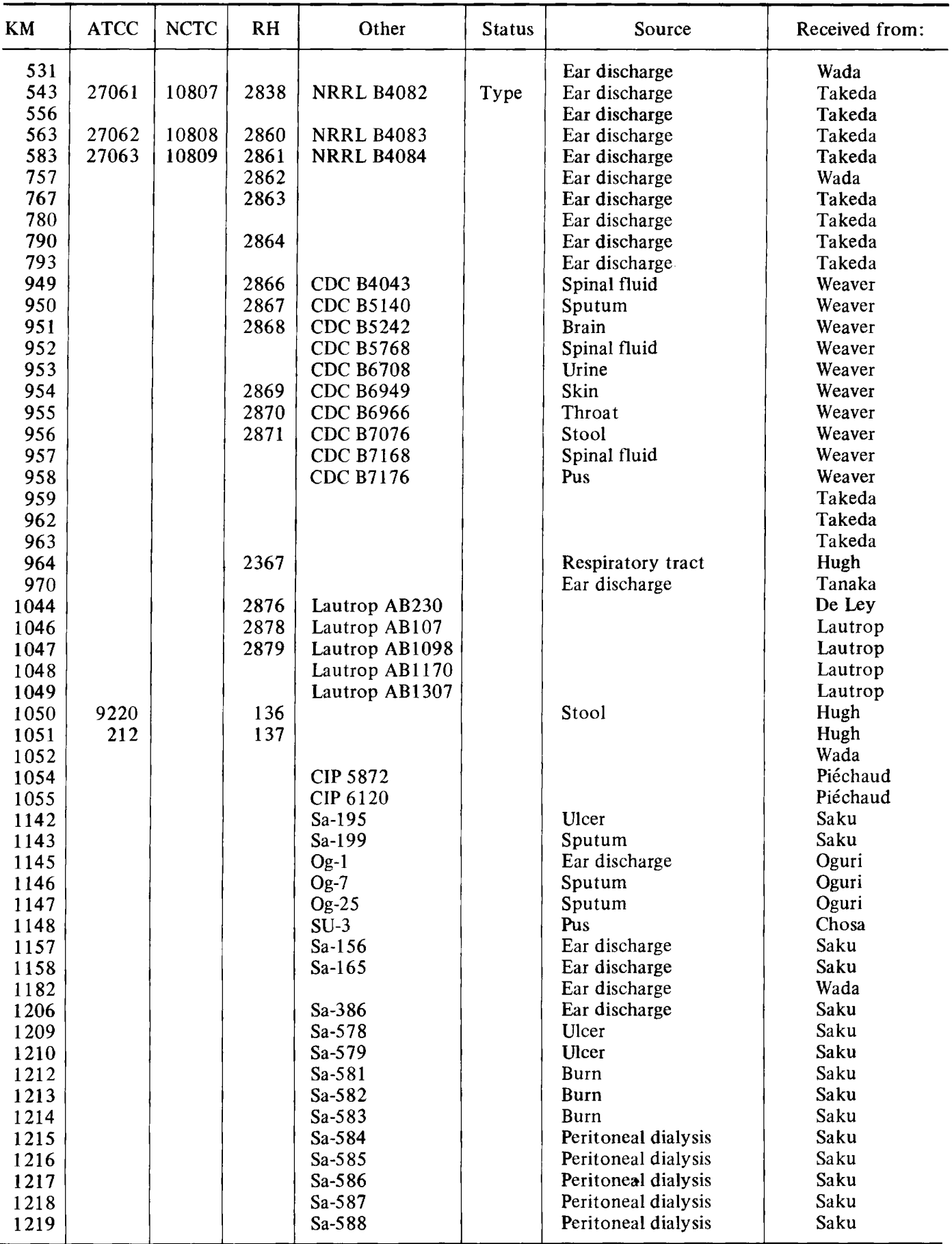

${ }^{a}$ Abbreviations: ATCC, American Type Culture Collection, Rockville, Md; CIP, Colléction de L'Institut Pasteur, Paris; CDC, Center for Disease Control, Atlanta Ga.; KM, Kansai Medical University Culture Collection, Osaka; NCTC, National Collection of Type Cultures, London; NRRL Northern Regional Research Laboratory, Peoria, Ill.; RH Rudolph Hugh, George Washington University, Washington D.C. 
TABLE 2. Nineteen strains described in the literature and subsequently identified as strains of Achromobacter xylosoxidans ${ }^{a}$

\begin{tabular}{c|l|l}
\hline $\begin{array}{c}\text { KM strain } \\
\text { no. }\end{array}$ & \multicolumn{1}{|c}{ Received as: } & \multicolumn{1}{|c}{ Reference } \\
\hline 949 & King group IIIa & King (6) \\
950 & King group IIIb & King (6) \\
951 & King group IIIb & King (6) \\
952 & King group IIIa & King (6) \\
953 & King group IIIb & King (6) \\
954 & King group IIIb & King (6) \\
955 & King group IIIa & King (6) \\
956 & King group IIIa & King (6) \\
957 & King group IIIb & King (6) \\
958 & King group IIIa & King (6) \\
1044 & Alcaligenes sp. AB230 & De Ley et al. (4) \\
1046 & Alcaligenes sp. AB107 & De Ley et al. (4) \\
1047 & Alcaligenes sp. AB1098 & De Ley et al. (4) \\
1048 & Alcaligenes sp. AB1170 & De Ley et al. (4) \\
1049 & Alcaligenes sp. AB1307 & De Ley et al. (4) \\
& & \\
1050 & Alcaligenes faecalis & ATCC catalogue \\
& RH 136 & (1) \\
1051 & A. faecalis RH137 & Moore and Pickett \\
& & (9) \\
1054 & A. denitrificans & De Ley et al. (4) \\
1055 & A. denitrificans & De Ley et al. (4) \\
& CIP 6120 & \\
\hline
\end{tabular}

${ }^{a}$ For abbreviations, see Table 1 , footnote $a$.

$\mathrm{KNO}_{3}, 2 \mathrm{~g}$; and distilled water, $1,000 \mathrm{ml}$ ); (iii) casitone-yeast extract broth (Casitone [Difco]), $10 \mathrm{~g}$; yeast extract [Difco], $3 \mathrm{~g}$; and distilled water, 1,000 ml; (iv) Casamino Acids broth (vitamin-free Casamino Acids [Difco 0288] $12 \mathrm{~g} ; \mathrm{K}_{2} \mathrm{HPO}_{4}, 1 \mathrm{~g} ; \mathrm{KH}_{2} \mathrm{PO}_{4}, 1$ $\mathrm{g} ; \mathrm{MgSO}_{4} \cdot 7 \mathrm{H}_{2} \mathrm{O}, 0.4 \mathrm{~g} ; \mathrm{NaCl}, 0.2 \mathrm{~g}$; and distilled water, $1,000 \mathrm{ml}$, sterilized by membrane filtration).

Anaerobic growth was compared with aerobic growth response in these four media. Indophenol oxidase activity was visualized by transferring growth from infusion agar to wet filter paper containing tetramethyl paraphenylendiamine hydrochloride (Nissui cytochrome-oxidase test paper). Sodium chloride tolerance was determined in brain heart infusion (BHI) broth containing 3,5 , or $6.5 \% \mathrm{NaCl}$. Sensitivity to sodium azide was determined in Streptococcus faecalis broth (Eiken). Ability to grow in the presence of $40 \%$ bile and hydrolyze esculin was determined in bile-esculin agar (Difco 0879).

Amidase activity was determined in the following medium (2): $\mathrm{KH}_{2} \mathrm{PO}_{4}, 2 \mathrm{~g} ; \mathrm{MgSO}_{4} \cdot 7 \mathrm{H}_{2} \mathrm{O}, 0.1 \mathrm{~g}$; $\mathrm{NaCl}, 5 \mathrm{~g}$; acetamide or propionamide, $1 \mathrm{~g}$; and distilled water, $1,000 \mathrm{ml}, \mathrm{pH} 6.8$. This medium was distributed in tubes in $1-\mathrm{ml}$ portions and autoclaved at $121 \mathrm{C}$ for $15 \mathrm{~min}$. A 24 -h agar slant culture of each strain was used to inoculate amidase medium. After incubation at $37 \mathrm{C}$ for 18 to $20 \mathrm{~h}, 1$ drop of Nessler reagent was added to each tube. Production of ammonium due to hydrolysis of amide was indicated by a red-brown precipitate.
Assimilation of glucose was determined in a chemically defined basal medium $\left[\mathrm{Na}_{2} \mathrm{HPO}_{4}, 7 \mathrm{~g}\right.$; $\mathrm{KH}_{2} \mathrm{PO}_{4}, 3 \mathrm{~g} ;\left(\mathrm{NH}_{4}\right)_{2} \mathrm{SO}_{4}, 1 \mathrm{~g} ; \mathrm{MgSO}_{4} \cdot 7 \mathrm{H}_{2} \mathrm{O}, 0.2 \mathrm{~g}$; and distilled water, $1,000 \mathrm{ml}$ ] containing a membranefiltered $10 \%$ glucose solution to make the final concentration $0.2 \%$. Growth from an 18 -h agar slant culture was harvested and suspended in sterile distilled water, and growth was diluted to a final concentration of $10^{6}$ cells $/ \mathrm{ml}$. One drop of this suspension was aseptically added to the medium with a sterile Pasteur pipette; the culture was incubated at $30 \mathrm{C}$ and observed daily. Cultures that produced a definite turbidity within 24 to $48 \mathrm{~h}$ and that could be maintained by serial subculture in the same medium were regarded as positive. Culture media that remained clear or became weakly turbid after 3 or more days were regarded as negative. Other physiological and biochemical tests listed in Table 3 were performed as reported previously $(13,14)$.

Sensitivities of the 55 strains to 17 antibiotics were determined by the twofold serial agar dilution method. One loopful of a bacterial suspension, a $10^{-2}$ dilution of an 18-h heart infusion broth culture, was streaked on the surface of the antibiotic-containing heart infusion agar plate. The minimal inhibitory concentration was read after $20 \mathrm{~h}$ of incubation at $37 \mathrm{C}$.

The GC ratios of the DNA of 14 selected strains were determined by J. De Ley.

The cellular lipid and fatty acid compositions of five selected strains, KM 543, 954, 955, 1047, 1051, were determined according to methods described previously (15).

\section{RESULTS}

The 55 strains of $A$. xylosoxidans studied contained gram-negative, asporogenous, straight rods with rounded ends. Capsules were not seen. Most cells appeared singly and some were in pairs. Soma size was 0.8 to $1.2 \times 2.5$ to 3.0 $\mu \mathrm{m}$. All strains except one (KM 953) were actively motile and peritrichous. Fifty-four strains, including the type strain, had one to nine normal peritrichous flagella. Strain KM 953 was nonmotile and atrichous after serial passage in motility medium in a petri dish. Figure 1 shows peritrichous cells of the type strain grown in a broth medium stained after

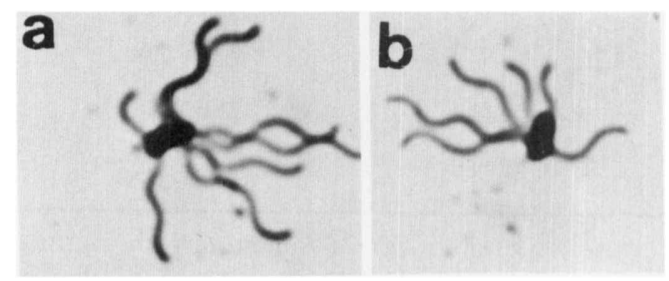

FIG. 1. Achromobacter xylosoxidans KM 543 peritrichous rods with nine (a) and six (b) peritrichous flagella. Broth culture. Leifson flagella stain after formalin fixation. $\times 2,000$. 


\begin{tabular}{|c|c|c|}
\hline Substrate or test ${ }^{a}$ & $\begin{array}{r}\text { Type strain } \\
\text { ATCC } 27061\end{array}$ & $\begin{array}{c}55 \text { strains }^{c} \\
\text { (\% positive) }\end{array}$ \\
\hline Gram-negative rod-shaped cells & + & 100 \\
\hline Motility & + & 98 \\
\hline Peritrichous flagella & + & 98 \\
\hline OF glucose medium open, acid & $t_{2}$ & $95(5)$ \\
\hline OF glucose medium sealed, acid & - & 0 \\
\hline Assimilation of glucose & + & 100 \\
\hline Oxidative acid production from ${ }^{d}$ : & & \\
\hline Ethanol (3\%) & $t_{3}$ & $24(76)$ \\
\hline Glycerol & $+t_{10}$ & $0(73)$ \\
\hline Adonitol, dulcitol, inositol & - & 0 \\
\hline Mannitol, sorbitol, xylitol & - & 0 \\
\hline Xylose & $t_{2}$ & 100 \\
\hline D-arabinose & $+t_{13}^{2}$ & $2(36)$ \\
\hline L-arabinose & - & $2(24)$ \\
\hline D-ribose & - & $0(9)$ \\
\hline Rhamnose & - & 0 \\
\hline Fructose & - & $16(11)$ \\
\hline Galactose & $t_{2}$ & $89(11)$ \\
\hline Mannose & $t_{2}^{2}$ & $58(42)$ \\
\hline Lactose, maltose, cellobiose & - & 0 \\
\hline Melibiose, sucrose, trehalose & - & 0 \\
\hline Raffinose, melezitose & - & 0 \\
\hline Inulin, salicin & - & 0 \\
\hline OF basal medium control, blue & + & 100 \\
\hline Indole, methyl red & - & 0 \\
\hline Acetylmethylcarbinol & - & 0 \\
\hline Indophenol oxidase, catalase & + & 100 \\
\hline Hydrogen sulfide, Kligler butt & - & 0 \\
\hline 2-Ketogluconate & $t_{2}$ & 62 \\
\hline 3-Ketolactose & - & 0 \\
\hline Malonate & $t_{2}$ & 100 \\
\hline Citrate, Simmons & + & 100 \\
\hline Nitrate reduction to nitrite & + & 100 \\
\hline Nitrite reduction to nitrogen gas & $t_{2}$ & 64 \\
\hline Water-soluble pigment & - & 0 \\
\hline Chloroform-soluble pigment & - & 0 \\
\hline Growth in BHI at $41 \mathrm{C}$ & + & 78 \\
\hline Growth in BHI at $\mathrm{pH} 4.5$ & - & 0 \\
\hline Growth in $\mathrm{BHI}$ containing $5 \% \mathrm{NaCl}$ & $t_{2}$ & $49(29)$ \\
\hline Growth in $\mathrm{BHI}$ containing $6.5 \% \mathrm{NaCl}$ & - & $0(9)$ \\
\hline Growth in SF broth & - & 0 \\
\hline Growth in the presence of $40 \%$ bile & + & $96(4)$ \\
\hline Growth on SS agar & + & 93 \\
\hline Growth on LD agar & + & 100 \\
\hline Growth on Pseudosel agar & - & 87 \\
\hline Growth on NAC agar & $t_{2}$ & $84(2)$ \\
\hline Lysine decarboxylase, Carlquist & - & 0 \\
\hline L-lysine decarboxylase, Møller & - & 0 \\
\hline L-arginine dihydrolase, Møller & - & 0 \\
\hline L-ornithine decarboxylase, Møller & - & 0 \\
\hline Phenylalanine deaminase & - & 0 \\
\hline Deoxyribonuclease, extracellular & - & 0 \\
\hline Amidase for propionamide & + & 100 \\
\hline Urease, phosphatase & - & 0 \\
\hline Gelatin liquefaction & - & 0 \\
\hline Hydrolysis of starch, Tween 80 & - & 0 \\
\hline Hydrolysis of esculin & - & 0 \\
\hline Hemolysis, rabbit blood agar & - & 0 \\
\hline Green discoloration, rabbit blood agar & - & 0 \\
\hline
\end{tabular}

a Abbreviations: BHI, brain heart infusion; LD agar, Leifson deoxycholate agar; NAC agar, nalidixic acid-cetrimide agar; SF broth, Streptococcus faecalis broth; SS agar, salmonella-shigella agar.

${ }^{b}$ Subscripts indicate days of incubation required for a positive reaction.

${ }^{c}$ Values indicate percent positive within 1 or 2 days. Values in parentheses indicate percent positive after 3 or more days.

${ }^{d}$ Carbohydrates except ethanol were used in $1.0 \%$ concentration. 
formalin fixation. Figure 2 shows peritrichous cells of the type strain grown on agar medium and stained without formalin fixation. The electron micrograph of the type strain (Fig. 3) shows the sheathed structure of the flagella.

A. xylosoxidans strains produced a homogenous turbidity in BHI broth within $24 \mathrm{~h}$ at room temperature, a pellicle and precipitate appeared and the broth became almost clear. Sixty-four percent of the strains reduced nitrate to nitrogen gas and grew luxuriantly under anaerobic conditions; the remaining $36 \%$ of the strains reduced nitrate to nitrite (not to nitrogen gas) and grew moderately well under anaerobic conditions. Casamino Acids broth, Casitone-yeast extract broth, and OF glucose medium did not support growth of the 55 strains under anaerobic conditions. They grew well in these media aerobically. Cultures of

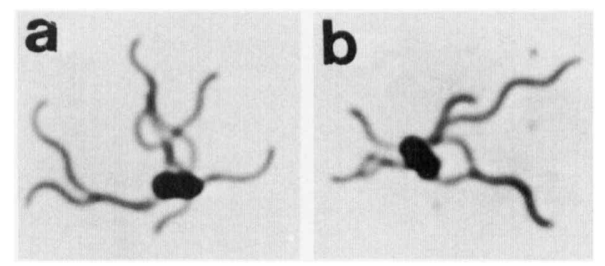

FIG. 2. Achromobacter xylosoxidans KM 543 peritrichous rods with eight (a) and seven (b) flagella. Infusion agar slant culture. Leifson flagella stain without formalin fixation. $\times 2,000$. these strains were serially maintained in a chemically defined broth medium containing glucose as a sole source of carbon and energy and ammonium ions as a sole source of nitrogen. They did not require growth factors.

After 2 days of incubation at $30 \mathrm{C}$, colonies on infusion agar medium were about $1 \mathrm{~mm}$ in diameter, smooth and glistening, and had an entire margin. Growth on infusion agar medium was grayish and semitranslucent, and after several days of incubation at room temperature it had a faint yellowish tint. Water-soluble pigment was not produced. Colonies on deoxycholate agar, salmonella-shigella agar, and nalidixic acid-cetrimede agar were discrete and gray. Rabbit erythrocytes in infusion agar medium were not hemolyzed around either discrete colonies or heavy growth. The blood agar medium around the colonies did not become greenish. The strains did not grow in BHI broth at $4 \mathrm{C}$ or in BHI broth adjusted to $\mathrm{pH} 4.5$. Forty-three $(78 \%)$ strains grew in $\mathrm{BHI}$ broth containing $5 \% \mathrm{NaCl}$, and only five $(9 \%)$ strains grew in BHI broth containing $6.5 \%$ $\mathrm{NaCl}$. All 55 strains grew on bile-esculin agar without blackening the medium, and none grew in $S$. faecalis broth. Acid promptly accumulated at the surface of unsealed OF basal medium containing xylose. Repeated examination revealed weak acid production in OF ethanol, galactose, glucose, and mannose media within 2 to 4 days. Alkali accumulated in OF basal

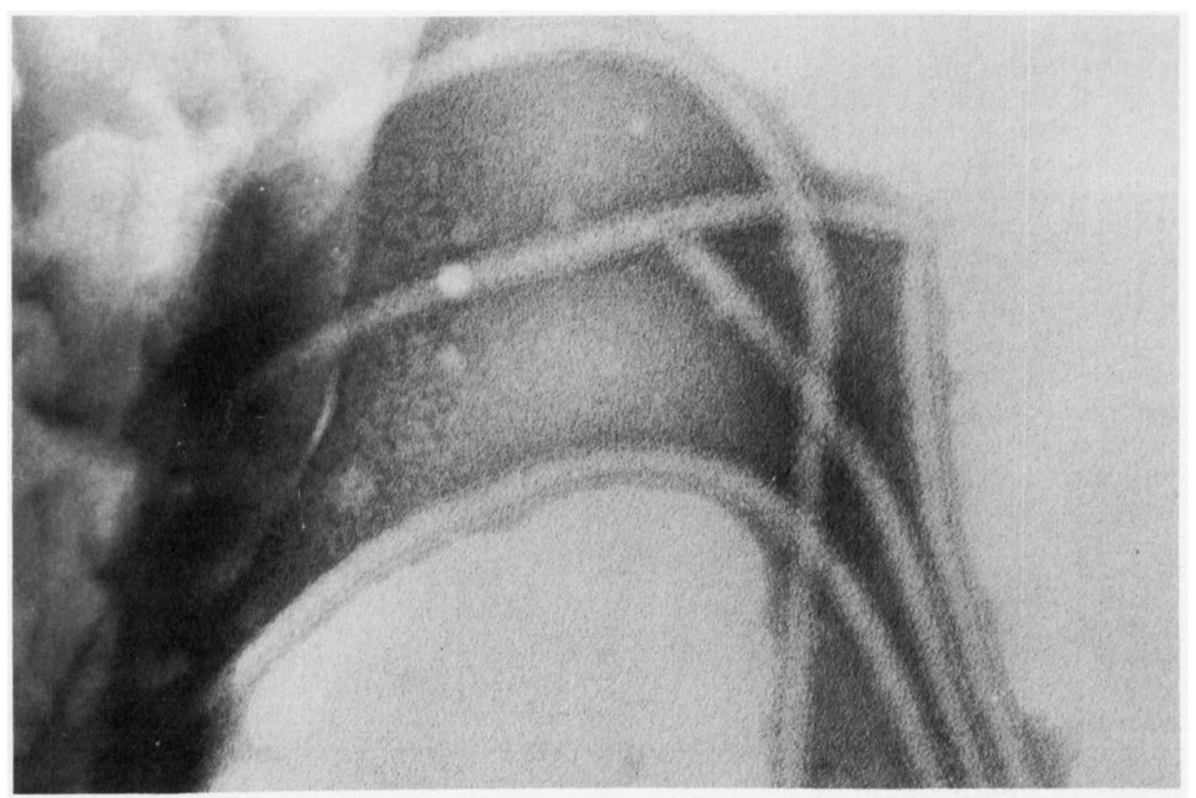

FIG. 3. Achromobacter xylosoxidans KM 543 peritrichous cells with sheathed flagella. Negatively stained with phosphotungstic acid after formalin fixation. $\times 200,000$. 
medium containing the following carbon compounds: rhamnose, cellobiose, lactose, maltose, sucrose, trehalose, melibiose, raffinose, melezitose, adonitol, dulcitol, inositol, mannitol, sorbitol, xylitol, inulin, and salicin. Simmons citrate and malonate media became alkaline. Indophenol oxidase, catalase, and amidase were produced. A stronger amidase reaction was observed in the propionamide medium than in the acetamide medium. Hydrogen sulfide was not detected in the butt of Kligler iron agar. Indole, acetylmethylcarbinol, and 3-ketolactose were not produced. Liquefaction of gelatin, hydrolysis of starch and Tween 80, phenylalanine deaminase, deoxyribonuclease, phosphatase, and urease reactions were negative. Carlquist ninhydrin tests for lysine decarboxylase, L-arginine dihydrolase, and L-lysine and L-ornithine decarboxylase reactions were negative in decarboxylase base $\mathrm{M} \phi$ ller (Difco 0890). Of the 55 strains, 20 were inhibited by rifampin at a concentration of $12.5 \mu \mathrm{g} / \mathrm{ml}$, and a few strains were inhibited by penicillin derivatives (Table 4). The GC contents of the DNA of 20 strains are recorded in Table 5; the values on six of these strains were reported by De Ley et al. (3).

Cardiolipin, phosphatidyl ethanol amine, and phosphatidyl glycerol were the major lipids extracted from five strains. The major fatty acid components of extractable lipids were C16:0, C16:1, C18:0, C18:1 straight-chain and $\mathrm{C} 17$ cyclopropanoic fatty acids. The major bound fatty acids in the five strains were 2-hydroxydodecanoic acid (25.6 to $33.6 \%$ ), 2-hydroxytetradecanoic (16.4 to $22.4 \%$ ), and 3-hydroxytetradecanoic ( 31.1 to $37.6 \%$ ).

\section{DISCUSSION}

The morphological, physiological, and biochemical characteristics, the GC contents of DNA, and the cellular lipid and fatty acid compositions of $A$. xylosoxidans strains are very uniform. A nonfermentative, gram-negative, asporogenous rod with the attributes listed in Table 6 can be identified as a strain of $A$. xylosoxidans. These minimal characters distinguish this species from pseudomonads, Enterobacteriaceae, Acinetobacter anitratus, and oxidase-positive peritrichous rods that fail to oxidize glucose and xylose. Although the original report on this stated that most of the seven strains of $A$. xylosoxidans failed to produce distinct acidity (the media remained neutral) in open tubes of OF media containing ethanol, glucose, galactose, and mannose, a reexamination revealed that a weak acidity (greenish-yellow, $\mathrm{pH} 6.5$ to 6.7 ) was produced from these four carbohydrates in OF media. All strains of $A$. xylosoxidans produced oxidative acidity from xylose. Some of the 55 strains slowly produced weak acidity from glycerol, Dand L-arabinose, D-ribose, and fructose. Acid was not produced from disaccharides, trisaccharides, polyalcohols inulin, or salicin.

The 55 strains failed to grow in OF glucose medium under anaerobic conditions. A. xylosoxidans is a strict aerobe. The 55 strains grew

TABLE 4. Antibiotic sensitivity of 55 Achromobacter xylosoxidans strains

\begin{tabular}{|c|c|c|c|c|c|c|c|c|c|c|c|}
\hline \multirow[b]{2}{*}{ Antibiotic } & \multicolumn{11}{|c|}{ No. of strains sensitive at concn $(\mu \mathrm{g} / \mathrm{ml})$ of: } \\
\hline & 0.19 & 0.39 & 0.78 & 1.56 & 3.12 & 6.25 & 12.5 & 25.0 & 50.0 & 100 & $>100$ \\
\hline Ampicillin & & 1 & & & 1 & & & & & 1 & 52 \\
\hline Carbenicillin & 2 & & & & & & 1 & & & 3 & 49 \\
\hline Sulbenicillin & & & 1 & 1 & & & & & 3 & 2 & 48 \\
\hline Cephalexin & & & & & & & & & & 4 & 51 \\
\hline Cephazolin & & & & & & 1 & & & & 3 & 51 \\
\hline Erythromycin & & & & & & & 1 & 1 & 2 & 7 & 44 \\
\hline Kitasamy cin & & & & & & & 1 & & 1 & 5 & 48 \\
\hline Rifampin & & & & & & 11 & 10 & 6 & & 2 & 26 \\
\hline Chloramphenicol & & & & & & & & 9 & 2 & & 44 \\
\hline Tetracycline & & & & & & & & 7 & 7 & 8 & 33 \\
\hline Streptomycin & & & & & & & & & & & 55 \\
\hline Kanamy cin & & & & & & & & & 6 & 5 & 44 \\
\hline Dideoxy-kanamycin B & & & & & & & & & 5 & 4 & 46 \\
\hline Gentamicin & & & & & & 2 & & 4 & 5 & 10 & 34 \\
\hline Polymyxin B & & & & & 1 & & 2 & 4 & 7 & 5 & 36 \\
\hline Colistin & & & & & & 3 & 2 & 1 & 3 & 3 & 43 \\
\hline Nalidixic acid & & & & & & & 3 & & 1 & 6 & 45 \\
\hline
\end{tabular}


TABLE 5. Guanine plus cytosine mole percent of 20 Achromobacter xylosoxidans strains ${ }^{a}$

\begin{tabular}{cl}
\hline KM strain no. & GC mol\% \\
\hline 563 & 66.9 \\
954 & 66.9 \\
956 & 67.4 \\
951 & 67.6 \\
955 & 67.9 \\
1047 & 68.1 \\
949 & 68.3 \\
1046 & $68.4^{b}$ \\
1049 & $684^{b}$ \\
757 & 68.6 \\
793 & 68.9 \\
1044 & $68.9^{b}$ \\
1048 & $68.9^{b}$ \\
790 & 69.0 \\
950 & 69.1 \\
543 & 69.2 \\
1055 & $69.2^{b}$ \\
583 & 69.5 \\
767 & 69.5 \\
1054 & $69.8^{b}$ \\
\hline
\end{tabular}

${ }^{a}$ Determined by J. De Ley. KM, Kansai Medical University Culture Collection, Osaka.

${ }^{b}$ Data from the report by De Ley et al. (4).

TABLE 6. Minimal characters for identification of Achromobacter xylosoxidans strains

\begin{tabular}{l|c|c}
\hline \multicolumn{1}{c|}{ Character } & $\begin{array}{c}\% \text { Posi- } \\
\text { tive }^{a}\end{array}$ & Sign \\
\hline Gram-negative, asporogenous, & 100 & + \\
$\quad$ straight rods & 98 & + \\
Peritrichous flagella & 98 & + \\
Motility & 100 & + \\
Indophenol oxidase & $95(5)$ & $+b$ \\
OF glucoso medium open, acid & 0 & - \\
OF glucose medium sealed, growth & 0 & - \\
OF maltose medium, acid & 100 & + \\
OF xylose medium, acid & 100 & + \\
Citrate, Simmons & 100 & + \\
Nitrate reduction to nitrite & 0 & - \\
Urease & 0 & - \\
Hemolysis and discoloration of & & \\
rabbit blood & 0 & - \\
Lysine decarboxylase, Carlquist & & \\
ninhydrin & 0 & - \\
\hline L-arginine dihydrolase &
\end{tabular}

${ }^{a}$ Based on a study of 55 strains. Values indicate percent positive within 1 or 2 days. Values in parentheses indicate percent positive after 3 or more days.

${ }^{b}$ Usually weaker than the acidity from xylose.

anaerobically in nitrate broth. Thirty-five (64\%) strains grew luxuriantly with copious bubbling in nitrate broth. The remaining 20 (36\%) strains grew moderately without gas production in nitrate broth under anaerobic conditions.
King (6) divided group III organisms into two groups: group IIIa strains reduced nitrate to nitrite and group IIIb strains reduced nitrate and nitrite to nitrogen gas. She felt that groups III a and IIIb belonged to the same species. Tatum (11) and Weaver et al. (12) feel that group IIIb can be regarded as a variant of group IIIa. From the results of the present study, it can be said that all known $A$. xylosoxidans strains grow anaerobically in the presence of nitrate and that the ability to reduce nitrate to nitrogen gas should be regarded as an infrasubspecific difference.

Fatty acid compositions of the extractable and bound lipids of five selected strains of $A$. xylosoxidans were very uniform. Nearly $80 \%$ or more fatty acids of the cellular bound lipids of five strains of the species were hydroxyfatty acids. The high concentration of hydoxyacids, especially $2-\mathrm{OH} 12: 0,1-\mathrm{OH} 14: 0$, and $3-\mathrm{OH} 14: 0$, in the bound lipids may prove to be characteristic of all $A$. xylosoxidans strains. A comparative investigation on the cellular lipid composition of several species of nonfermentative, gram-negative, peritrichous rods will be published elsewhere.

Although the absence of a type or neotype strain for Achromobacter liquefaciens, type species of the genus, has made it difficult to determine what other species should be included in the genus Achromobacter, A. xylosoxidans was included in the genus Achromobacter on the basis of the following definition of the genus (4): gram-negative, asporogenous, motile rods; peritrichous; OF glucose medium open, acid $(+)$ or no change; OF glucose medium sealed, acid ( $(-)$; indophenol oxidase and catalase $(+) ; 3$-ketolactose $(-)$.

Though the natural habitat is now known, $A$. xylosoxidans has been isolated from various kinds of pathological specimens, such as blood, spinal fluid, pleural fluid, peritoneal fluid, pus, urine, stool, and swabs of eye, ear, and pharynx. The occurrence of strains of $A$. xylosoxidans in pathological specimens warrants an investigation of the clinical significance of the species. Shigeta et al. (9) reported a 9-year-old girl with purulent meningitis caused by $A$. xylosoxidans. The meningitis occurred in May and again in September after occipital trepanation and ventriculoperitoneal shunt in March. A. xylosoxidans was isolated from spinal fluid in pure culture. The patient's serum agglutinated the isolates up to a dilution of $1: 640$. During the later stage of preparation of this manuscript in 1974, Y. Kanazawa (Niigata Railway Hospital, Japan) related (personal communication to E. Y.) that a nonfermentative, gram-negative, motile rod was isolated in 
pure culture from arterial blood, venous blood, and a biopsy specimen of a cervical lymph node of a 42-year-old male patient with remittent fever and cervical lymph node swelling. The three isolates were very much alike and were very sensitive to chloramphenicol among eight antibiotics tested. The patient was effectively treated with chloramphenicol. The three isolates, 1547,1548 , and 1549 , were received from Kanazawa and identified as strains of $A$. xylosoxidans.

\section{ACKNOWLEDGMENTS}

We are grateful for the generosity of those who supplied bacterial strains and for J. De Ley's assistance in determining the GC composition of DNA. We are deeply indebted to R. Hugh for his helpful suggestions and comments. The efforts of H. Yabuuchi, Jr., in the preparation of the photomicrographs are greatly appreciated.

\section{REPRINT REQUESTS}

Address reprint requests to: Dr. Eiko Yabuuchi, Kansai Medical University, Department of Microbiology, Moriguchi, Osaka 570, Japan.

\section{LITERATURE CITED}

1. American Type Culture Collection. 1949. Catalogue of strains, 5th ed., p. 4. American Type Culture Collection, Rockville, Md.

2. Arai, T., M. Otake, S. Enomoto, S. Goto, and S. Kuwahara. 1970. Determination of Pseudomonas aeruginosa by biochemical test method. III. Acylamidase test. Jap. J. Microbiol. 14:279-284.

3. De Ley, J., K. Kersters, J. Khan-Matsubara, and J. M. Shewan. 1970. Comparative D-gluconate metabolism and DNA base composition in Achromobacter and Alcaligenes. Antonie van Leeuwenhoek J. Microbiol. Serol. 36:193-207.
4. Hugh, R. 1970. A practical approach to the identification of certain nonfermentative Gramnegative rods encountered in clinical specimens. Publ. Health Lab. 28:168-187.

5. Hugh, R. 1970. Pseudomonas and Aeromonas, p. 175-190. In J. E. Blair, E. H. Lennette, and J. P. Truant (ed.), Manual of clinical microbiol. American Society for Microbiology, Bethesda, Md.

6. King, E. O. 1964. The identification of unusual pathogenic Gram-negative bacteria. CDC Publication.

7. Leifson, E. 1951. Staining, shape, and arrangement of bacterial flagella. J. Bacteriol. 62:377389.

8. Leifson, E. 1960. Atlas of bacterial flagellation. Academic Press Inc., London and New York.

9. Moore, H. B., and M. J. Pickett. 1960. The Pseudomonas-Achromobacter group. Can. J. Microbiol. 6:35-42.

10. Shigeta, S., K. Higa, M. Ikeda, and S. Endo. 1974. A purulent meningitis caused by Achromobacter xylosoxidans. (In Japanese) Igaku No Ayumi 88:336-337.

11. Tatum, H. W. 1970. Miscellaneous Gram-negative bacteria, p. 191-198. In J. E. Blair, E. H. Lennette, and J. P. Truant (ed.), Manual of clinical microbiology. American Society for Microbiology, Bethesda, Md.

12. Weaver, R. E., H. W. Tatum, and D. G. Hollis. 1972. The identification of unusual pathogenic Gram-negative bacteria (E. O. King). Preliminary revision. CDC Publication.

13. Yabuuchi, E., and A. Ohyama. 1971. Achromobacter xylosoxidans $\mathrm{n}$. sp. from human ear discharge. Jap. J. Microbiol. 15:477-480.

14. Yabuuchi, E., and A. Ohyama. 1972. Characterization of pyomelanin-producing strains of Pseudomonas aeruginosa. Int. J. Syst. Bacteriol. 22: 53-64.

15. Yano, I., Y. Furukawa, and M. Kusunose. 1970. 2-Hydroxy fatty acid-containing phospholipid of Arthrobacter simplex. Biochim. Biophys. Acta 210:105-115. 